\title{
Espondilodiscite brucelósica: relato de caso
}

\author{
Brucella spondylodiscitis: case report \\ César Ribeiro Ferreira', Celso Ribeiro Ferreira', Thiago Andrade Tatagiba² \\ e João Tadeu Damian Souto Filho ${ }^{3}$
}

Resumo A localização vertebral da brucelose apresenta ocorrência pouco freqüente atualmente. Por este motivo é indispensável a atenção para as modificações estruturais no segmento vertebral causadas pela espondilodiscite bacteriana. A partir do caso clínico, em que se relatam aspectos radiográficos, anatomopatológicos e laboratoriais relacionados ao diagnóstico, bem como ao tratamento desta doença, chamase a atenção para sua importância, e para as graves conseqüências em caso de demora para a definição diagnóstica.

Palavras-chaves: Brucella. Brucelose. Inflamação. Coluna vertebral. Epondilodiscite.

Abstract Vertebral localization of Brucellosis has a low occurrence nowadays. Because of its rarity, it is essential to pay attention to structural modifications of the vertebral segment caused by bacterial spondylodiscitis. Based on a clinical case, with radiological, anatomicopathological and laboratorial aspects related to the diagnostic and also the treatment of this disease, the authors underscore the importance and serious consequences arising from a late diagnostic definition.

Key-words: Brucella. Brucellosis. Inflammation. Vertebral column. Spondylodiscitis.

Em tempos atuais, a freqüência de casos relatados de brucelose de localização vertebral vem reduzindose a taxas mínimas. Na vigência da expansão da pasteurização do leite e de seus derivados, do maior controle das carnes consumidas e de estímulos à vacinação de animais, aliados a antibioticoterapia corriqueira, abrangente e capaz de proporcionar tratamento eficaz e seguro, obteve-se uma drástica redução de casos de brucelose observados.

Tendo por base a patologia em questão e a partir do relato do caso clínico, busca-se proporcionar um subsídio a mais, para ser acrescentado ao conjunto de hipóteses existentes na firmação do diagnóstico diferencial dos variados processos patológicos vertebrais.

São discutidos, assim, aspectos clínicos, radiográficos, anatomopatológicos e laboratoriais relacionados a este acometimento vertebral, bem como os resultados obtidos através da terapêutica específica, com a melhora do quadro clínico. Tem-se, portanto, o objetivo de chamar a atenção e conscientizar para o diagnóstico de brucelose.

\section{RELATO DO CASO}

Paciente MCS, sexo feminino, 43 anos, branca, proveniente do meio rural do Estado da Paraíba, foi atendida no ambulatório do Hospital Universitário de Fortaleza com dor abdominal em flanco direito, com início há aproximadamente 90 dias, de curso insidioso e persistente, com irradiação para a região glútea bilateralmente e região posterior da coxa direita, estendendo-se até o joelho. A dor intensificou-se até tornar-se incapacitante, a ponto de dificultar a deambulação da paciente. Concomitantemente, a este quadro, apresentou febre baixa $\left(38^{\circ} \mathrm{C}\right)$, principalmente no período vespertino, sem calafrios ou sudorese significativa. Apresentou também anorexia, inapetência e perda de cerca de $15 \mathrm{~kg}$ neste período.

Ao exame físico, apresentou-se em regular estado geral, bem orientada no tempo e no espaço, emagrecida, mucosas hipocoradas $++/ 4$, anictérica, eupnéica e acianótica, sem alterações musculares ou cutâneas. Manobra de Lasegue positiva à direita e reflexo patelar exacerbado.

1. Serviço de Diagnóstico por Imagem da Ecoclínica, João Pessoa, PB. 2. Hospital São Vicente de Paulo, Bom Jesus do Itabapoana, RJ. 3. Faculdade de Medicina de Campos, Campos dos Goytacazes, RJ.

Endereço para correspondência: Dr. João Tadeu Damian Souto Filho. Rua João Sobral Bittencourt 41/204, Parque Tamandaré, 28030-120 Campos dos Goytacazes, RJ.

Tel: 5522 2723-5727

E-mail: joaotad@censa.com.br

Recebido para publicação em 20/7/1999. 
Ausência de linfadenopatias cervicais, axilares e inguinais. Aparelho cardiovascular com ritmo regular em 2 tempos, bulhas normofonéticas e sem sopros. Aparelho respiratório com expansibilidade mantida, murmúrio vesicular presente e ausência de ruídos adventícios bilateralmente. Abdome com cicatriz umbilical, ausência de visceromegalias e indolor à palpação superficial e profunda.

Hemograma completo apresentou leucocitose, com lifocitose relativa, ausência de granulações tóxicas grosseira e VHS aumentado. As sorologias para VDRL e HIV negativas e o PPD não reator.

O Raio $X$ simples de abdome e o Raio $X$ de tórax mostraram-se normais. O Raio $X$ de coluna lombar apresentou escoliose destro-côncava e redução do espaço discal entre L4/L5. A ultra-sonografia de abdome total revelou massa retroperitoneal à direita, de natureza a esclarecer.

A ressonância magnética com contraste demonstrou grave anormalidade com captação de contraste envolvendo o músculo psoas, o disco intervertebral e os corpos vertebrais de L4/L5, notando-se material amorfo obliterando a raiz espinhal à direita de $L 5$, invadindo o canal raquiano e associado à destruição das margens ósseas articulares. Os achados são compatíveis com espondilodiscite em L4/L5, associada a abscesso epidural e do músculo psoas direito.(Figuras 1 e 2).

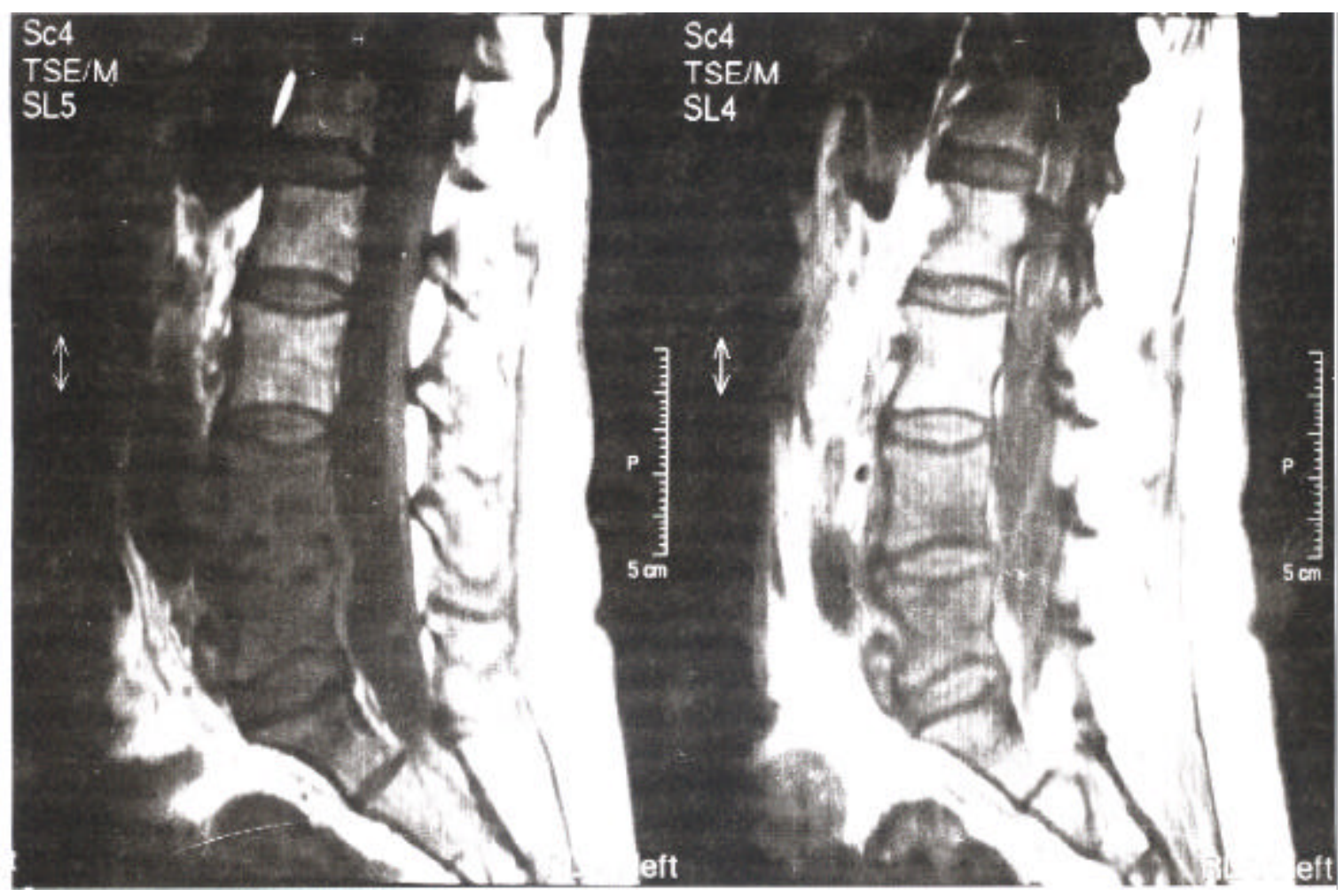

Figura 1 - Ressonância magnética contrastada em corte sagital no nível dos segmentos lombares 4 e 5 , evidenciando diminuição do espaço intervertebral entre L4 e L5, associado a destruição de margens ósseas de L5. Nota-se material amorfo, infiltração è edema perivertebral.

Após estes dados deu-se início ao uso de medicação específica para tuberculose e tentou-se punção do local acometido para exame laboratorial, sem sucesso.

Uma intervenção cirúrgica para estabilização da coluna vertebral e drenagem descompressiva mostrouse necessária ${ }^{3}$. Através deste procedimento, se evidenciou um material purulento com áreas de necrose e presença de fragmentos ósseos, com volume de cerca de $60 \mathrm{ml}$ de material inflamatório espesso retirados do local. Após a drenagem cirúrgica, com esvaziamento do espaço epidural, a paciente obteve significativa melhora dos sintomas.
As modificações estruturais no segmento vertebral apresentam-se como uma lesão granulomatosa formando pequenos abscessos irregulares, no corpo ou no disco, intercaladas por zonas de destruição e matéria caseosa. Essas alterações estão intimamente correlacionadas ao aspecto radiológico, demonstrando a conservação dos contornos do corpo vertebral; epifisite do ângulo vertebral anterior com formação géodica intraesponjosa; e proliferação osteofitária através dos espaços intervertebrais com formação de pontes ósseas estendendo-se ao corpo adjacente ${ }^{131015}$. 


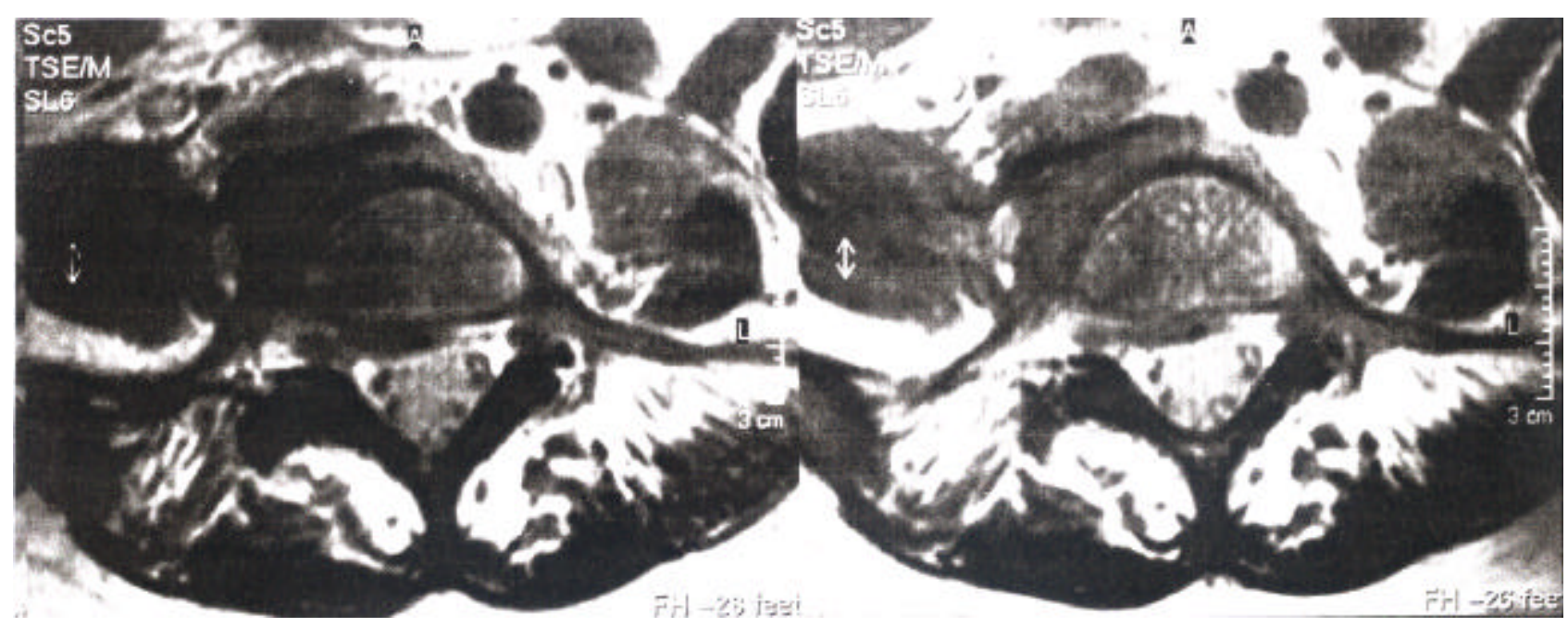

Figura 2 - Resonância magnética contrastada em corte axial no nível dos segmentos lombares 5 e 6 , observando-se material amorfo obliterando a raiz espinhal direita de L5, associado a anormalidades de captação de contraste envolvendo o músculo psoas direito.

Foram enviados fragmentos do material tecidual para análise laboratorial a fim de se traçar o diagnóstico. O exame histopatológico revelou a presença de processo inflamatório granulomatoso não específico. A bacterioscopia mostrou a presença de cocobacilos pequenos e gram-negativos. E através da hemocultura, enriquecida com $\mathrm{CO}_{2}$, obteve-se crescimento lento, de colônias pequenas, apigmentares, não hemolíticas, convexas, úmidas e brilhantes, compatíveis com Brucella.

O tratamento envolveu medidas gerais, com repouso no leito, devido à dificuldade para deambulação. Utilizou-se analgésicos e antiinflamatórios como medidas de alívio. O esquema terapêutico antimicrobiano envolveu a associação de tetraciclina e estreptomicina, durante três meses, sendo que a estreptomicina foi prescrita durante as três primeiras semanas.

Após o tratamento, juntamente com a estabilização vertebral, o quadro álgico reduziu, persistindo mediante movimentos bruscos. Apresentava-se apirética, e com o ganho ponderal de $8 \mathrm{~kg}$.

\section{DISCUSSÃO}

A brucelose, infecção bacteriana causada pelo gênero Brucella, é uma zoonose de distribuição mundial ${ }^{813}$. Continua sendo um problema mundial de saúde pública, com cerca de 500.000 casos de infecção ao ano. É de grande importância ressaltar que a brucelose humana é subdiagnosticada, com a estimativa de que pelo menos 25 casos não são reconhecidos para cada caso diagnosticado ${ }^{9}$.

Esta patologia compromete em geral trabalhadores que mantêm contato freqüente com animais e seus produtos. A sua transmissão, para humanos, ocorre principalmente por ingestão, contato direto, inoculação, e inalação, ou seja, pela mucosa digestiva, pela pele íntegra ou lesada ou também por via respiratória. A principal fonte de infecção por ingestão é representada por leite e derivados, principalmente queijo fresco. Carne crua ou mal passada, principalmente de suínos, e verduras não cozidas, que foram irrigadas com água contaminada ou adubadas com esterco animal, também podem ser fontes de infecção ${ }^{10}{ }^{13}$.

A brucelose pode se apresentar como infecção ou como doença. A infecção brucélica é caracterizada pela presença de anticorpos séricos anti-brucela, na ausência de sintomatologia. Já a brucelose doença é caracterizada, de uma forma geral, por episódios septicêmicos agudos, seguida por uma fase crônica, podendo comprometer vários órgão e tecidos ${ }^{13}$. Febre, calafrios, sudorese, fadiga, acompanhados de cefaléia, mialgia, artralgia, anorexia e emagrecimento são as manifestações clínicas mais freqüêntes ${ }^{191213}$. A febre tende a ser mais elevada em períodos agudos, e do tipo remitente, ou ondulante; os períodos crônicos são em geral afebris. Seguem também astenia, esplenomegalia, linfadenopatia, hepatomegalia e rigidez de nuca ${ }^{12}{ }^{13}$.

Outros órgãos, aparelhos e sistemas podem estar comprometidos, constituindo complicações da brucelose. Estas complicações incluem, invasão do aparelho esquelético, do sistema nervoso central, do trato respiratório, trato gastrointestinal, sistema cardiovascular e pele ${ }^{913}$.

Os envolvimentos ósseo e articular são apontados como complicações de incidência com relativa importância, de cerca de $23 \%$ dos casos $^{7}$, variando de acordo com o local. Artralgias periféricas, 
particularmente de grandes articulações, são a mais comum manifestação osteoarticular ${ }^{2}$, compondo a grande maioria dos $\operatorname{casos}^{7}$. Em segundo, encontram-se as sacroilítes unilaterais, envolvendo a articulação sacroilíaca. E a espodilite é relatada como apresentando baixa incidência, ocorrendo em $6 \%^{6} 14$ a $9 \%^{7}$ dentre as manifestações osteoarticulares ${ }^{6}$ e representam apenas $1 \%$ a $2 \%$ dentre todos os casos de brucelose.

Este caso ilustra um quadro de síndrome consumptiva associada a uma lombociatalgia, com exame radiológico simples de coluna vertebral e ultrasonografia de abdome revelando escoliose e a presença de massa retroperitoneal, respectivamente. Devido a este fato, pensou-se primeiramente na presença de um processo neoplásico. Mas, a partir do exame de ressonância magnética, sugeriu-se a presença de processo inflamatório e não de neoplásia, como se havia pensado primeiramente.

O diagnóstico precoce da espondilodiscite brucelósica apresenta grande dificuldade devido ao longo período latente de infecção ${ }^{11}$. O aspecto clínico não é muito típico, exceto pelo comprometimento vertebral circunscrito, e com freqüência a doença não se manifesta por sinais claros de inflamação e infecção ${ }^{4}$. Assim, a valorização de antecedentes epidemiológicos é necessária para se estabelecer o diagnóstico, pois não há sinal ou sintoma patognomônicos ${ }^{17}$.

Soube-se tratar de um processo inflamatório pela identificação do acometimento de disco intervertebral e de corpos vertebrais, sem entretanto se demonstrar qualquer acometimento de pedículo vertebral, como ocorre geralmente nos processos neoplásicos. Os abscessos epidural e do músculo psoas direito, provavelmente foram os responsáveis pela falsa identificação de uma massa retroperitoneal, revelada pelo exame de ultra-sonografia.

O exame de ressonância magnética foi de grande utilidade para a elucidação diagnóstica, pois através deste suspeitou-se de um processo inflamatório que, em primeira instância, teve como hipótese diagnóstica o acometimento por Mycobacterium tuberculosis. E, como, a espondilodiscite causada por Brucella é indistingüível radiologicamente das causadas por outros microorganismos ${ }^{17}$, somente após o procedimento cirúrgico e coleta do material para exame histopatológico e bacteriológico é que se descobriu tratar-se de uma espondilodiscite brucelósica.

A adoção do esquema terapêutico após os exames diagnósticos proporcionou uma melhor seleção dos antimicrobianos utilizados, cuja escolha foi baseada em tratados e livros textos de doenças infecto-parasitárias ${ }^{13}$.

Devido à possibilidade de processos inflamatórios de coluna vertebral simularem neoplasias, bem como a necessidade de se estar atento para a presença de infecções brucelósicas e suas complicações, é que se chama a atenção para a existência desta etiologia, bem como das graves conseqüências em caso de demora para definição diagnóstica.

\section{REFERÊNCIAS BIBLIOGRÁFICAS}

1. Al-Eissa YA, Kanbal AM, Alrabeeah AA, Abdullah Am, Al-Jurayyan NA, Al-Jishi NM. Osteoarticular Brucellosis in children. Annals of the Rheumatic Diseases 49: 869-900, 1990.

2. Al-Rawi ZS. Al-Khateeb N, Khalifa SJ. Brucella arthritis among Iraqi patients. British Journal of Rheumatology 26: 24-27, 1987.

3. Ariza J. Brucellar Spondylitis: A detailed analysis based on current findings. Review of Infectious Diseases 7: 656-664, 1985.

4. Bodmer K. Brucella Spondylodiskitis. Schweizerisch Medicinishe Wochenschrift, 24, 115: 1160-1165, 1985.

5. Colmenero JD, Cisneros JM, Orjuela DL, Pachón J, GarciaPortales R, Rodriguez-Sampedro F, Juarez C. Clinical curse and prognosis of Brucella Spondylitis. Infection 20: 38-42, 1992.

6. Gotuzzo E, Alarcón GS, Bocanegra TS, Carrilo C, Guerra JC, Rolando I, Espinoza LR. Articular involvement in human brucellosis: a retrospective analysis of 304 cases. Seminars in Arthritis and Rheumatism, 12: 245-255, 1982.

7. Gotuzzo E. Brucellar Arthritis: A study of 39 peruvian families. Annals of the Rheumatic Diseases 46: 506-507, 1987.

8. Jawetz E, Melnick JL, Adelberg EA, Brooks GF, Butel JS, Ornston LN. Microbiologia Médica. Guanabara Koogan, Rio De Janeiro cap 19, p.195-200, 1991.

9. Koneman EW. Color Atlas And Textbook of Diagnostic Microbiology. $5^{\text {th }}$ edition: Lippincott-Raven Publishers, Philadelphia p. 431-436, 1997.
10. Lima P. Espondilite Brucelosa Lombar. Revista do Colégio Brasileiro de Cirurgiões 8: 70-73, 1981.

11. Maiuri F, laconetta G, Gallicchio B, Manto A, Briganti F. Spondylodiscitis: clinical and magnetic resonance diagnosis. Spine 22: 1741-1746, 1997

12. Malik GM. A clinical study of brucellosis in adults in the Asir region of Southern Saudi Arabia. American Journal of Tropical Medicine nad Hygiene 56: 375-377, 1997.

13. Mendes RP, Machado JM. Brucelose. In: Veronesi R, Focaccia R (eds) Tratado de Infectologia. Editora Atheneu, São Paulo p. 575-582, 1996.

14. Mousa AR, Muhtaseb AS, Almudallal DS, Khodeir SM, Marafie AA. Osteoarticular complications of brucellosis: a study of 169 cases, Review of Infectious Diseases 9: 521 543, 1987.

15. Rajapakse CN. Bacterial infections: osteoarticular brucellosis. Baillieres Clinical Rheumatology 9: 161-177, 1995.

16. Samra $Y$, Hertz M, Shaked $Y$, Zwas S, Altman G. Brucellosis of the spine. a report of 3 cases. Journal of Bone and Joint Surgery, 64: 429-431, 1982.

17. Tekkök IH, Berker M, Ozcan OE, Ozgen T, Akalin E. Brucellosis of the spine. Neurosurgery 33: 838-844, 1993. 